\title{
INCORPORAÇÃO DO REJEITO DE MÁRMORE E GRANITO EM MATRIZ POLIMÉRICA
}

\author{
A. C. A. SOUSA ${ }^{1}$, T. S. CARVALHO ${ }^{1}$, I. F. SANTOS ${ }^{2}$ e M. H.V da SILVA ${ }^{3}$ \\ 1,3 Instituto Federal do Pará, Coordenação de Engenharia de Materiais \\ ${ }^{2}$ Universidade Federal do Pará, Programa de Pós Graduação em Engenharia de Recursos \\ Naturais da Amazônia \\ E-mail para contato: carolina_sousa3@yahoo.com.br
}

\begin{abstract}
RESUMO - A utilização de resíduos provenientes da indústria de beneficiamento de mármore e granito como aditivos na fabricação de produtos compósitos vem despertando interesse acadêmico e industrial nos últimos anos. Este trabalho objetiva avaliar a produção de compósitos a partir desses resíduos, utilizando resina poliéster isoftálica como matriz agregante e contendo fibra de coco em uma porcentagem mássica de $1 \%$ em relação ao peso da placa. Adotou-se $0 \%$ de resíduo como padrão de comparação para os demais corpos de prova, cada um contendo $10,20,30,40$ e $50 \%$ de resíduo em substituição à resina. Foram realizados ensaios experimentais para obtenção de valores de massa específica aparente, absorção de água e porosidade aparente para avaliar a influência da quantidade de resíduo nessas propriedades. Os resultados alcançados confirmam a eficácia da inserção desse resíduo na matriz polimérica para uso como material alternativo e de menor impacto ambiental.
\end{abstract}

\section{INTRODUÇÃO}

A prática da sustentabilidade é um desafio do século XXI, assim novas metodologias são adotadas para possibilitar a plena execução das atividades sem deteriorar o meio ambiente, contribuindo para qualidade de vida sem necessariamente agredir o crescimento econômico. No Brasil há quantidades significativas de resíduos de produção, para este trabalho destacamos duas, a fibra de coco e resíduos de mármores ou granitos.

O resíduo em forma de lama é constituído principalmente de carbonato de cálcio, um mineral muito utilizado como carga em polímeros para aumentar a estabilidade térmica e dimensional, além de diminuir custo de matéria-prima para confecção de peças plásticas. (Ferreira e Nunes, 2007).

A incorporação de cargas minerais e fibras naturais em matrizes poliméricas, especialmente a de poliéster insaturado tem se tornando a forma mais viável para se originar a iniciativa da linha de novos materiais, devido as suas propriedades específicas, baixo custo e sustentabilidade econômica. (Santos)

A adição destas cargas de reforço é uma alternativa viável, podendo melhorar as propriedades dos polímeros reciclados e torná-los competitivos em relação aos polímeros virgens. (Rabello, 2000, p.173). Levando-se em consideração ainda que esses rejeitos seriam 
descartados na natureza, trazendo riscos e poluição, o processo de reaproveitamento torna-se mais vantajoso.

\section{OBJETIVO}

Confeccionar compósitos a partir de resíduo de mármore e granito utilizando resina de poliéster insaturado como matriz agregante e avaliar a influencia do aumento de resíduo em substituição à resina, através das variações da massa específica aparente, porosidade aparente e absorção de água do material.

\section{MATERIAIS E MÉTODOS}

Foram confeccionadas placas retangulares de compósitos de poliéster insaturado preenchido com carga de RMG e fibra de coco, nas dimensões $320 \mathrm{~mm}$ x $170 \mathrm{~mm}$ x $5 \mathrm{~mm}$. Posteriormente essas placas foram cortadas em corpos de prova nas dimensões $250 \mathrm{~mm}$ x 25 $\mathrm{mm} \times 5 \mathrm{~mm}$ para a determinação da mea, pa e aa.

Materiais: A resina AM 910, o acelerador de cobalto e o iniciador MEK-P (Butanox M50), mostrados na figura 1, foram produzidos pela empresa AEROJET Brasileira de Fiberglass 1tda, conforme a Figura 1, assim como o desmoldante Desmoljet.

Figura 1 - Resina de poliéster insaturado (a), iniciador peróxido de etil-metil cetona (MEK-P) (b) e acelerador de cobalto (c).

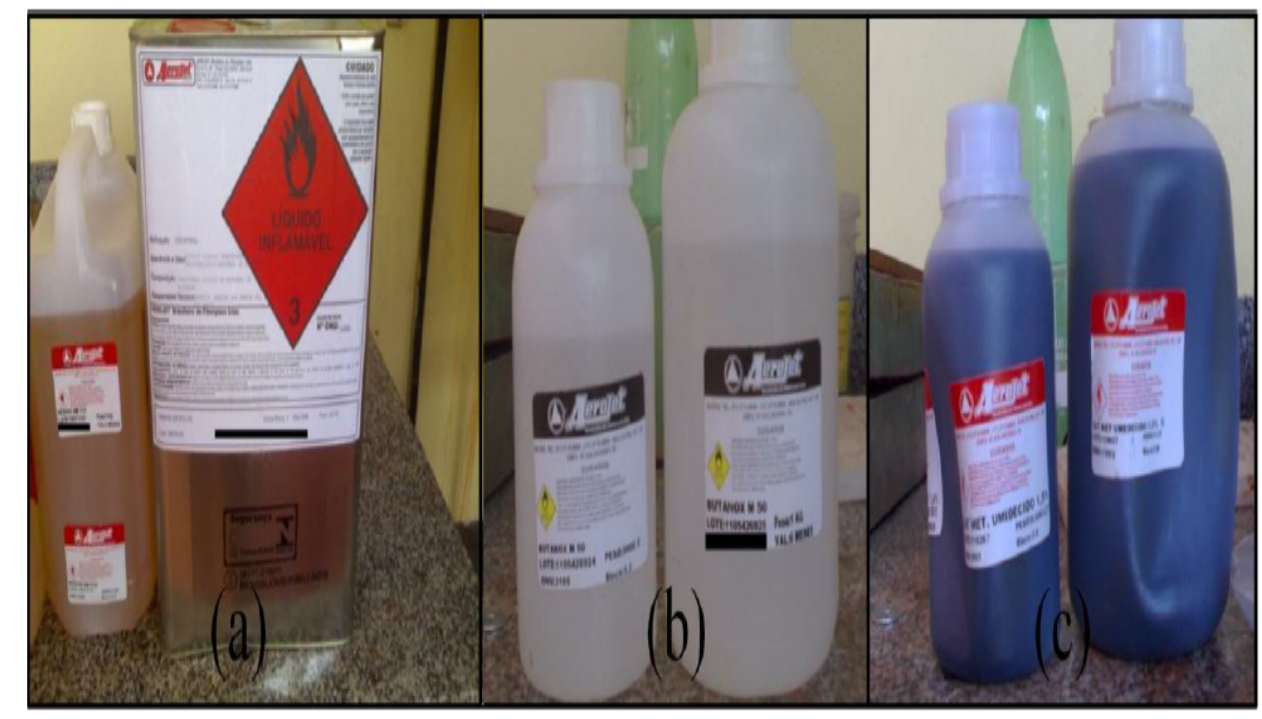

O resíduo de mármore e granito, Figura 2, foi disponibilizado pela empresa Brilasa Britagem e Laminação de Rochas S/A e a fibra de coco, vista na Figura 3, foi doada por agricultores, da região metropolitana de Belém. 
Figura 2 - Rejeito de mármore e granito

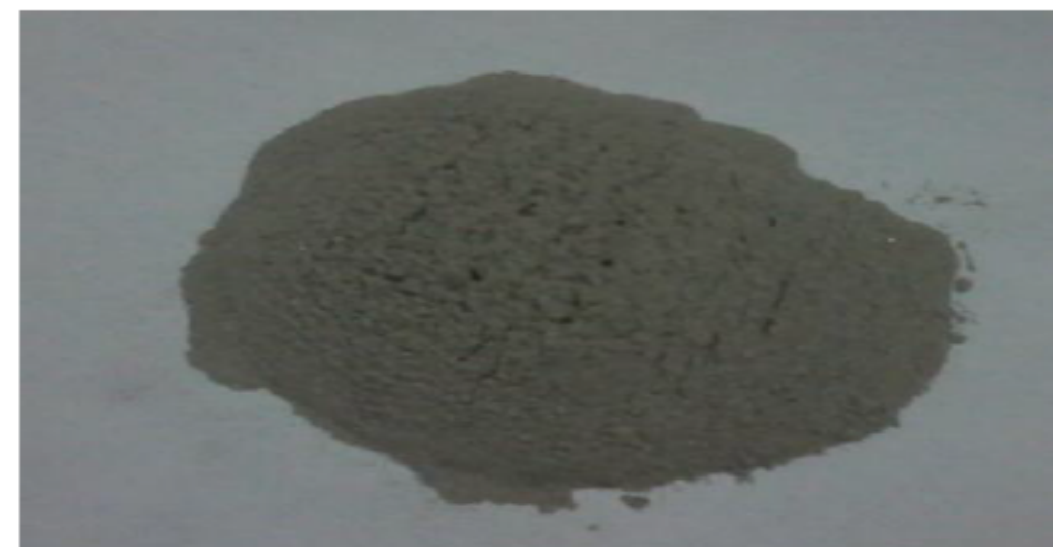

Figura 3 - Fibra de coco

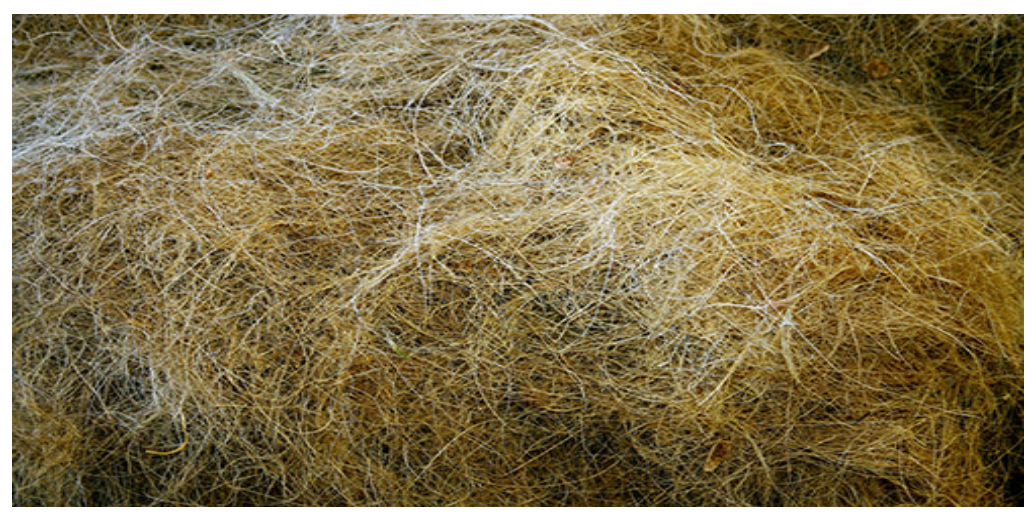

Métodos: Foram confeccionados corpos de prova conforme mostrados na Figura 4, pelo método Hand Lay up. Neste método as fibras são dispostas sobre a superfície do molde, impregnadas com a mistura (resina e rejeito de mármore e granito) de maneira manual. A espessura é obtida através da sobreposição das fibras e resina.

Figura 4 - Corpos de prova em porcentagem crescente de RMG da esquerda para a direita.

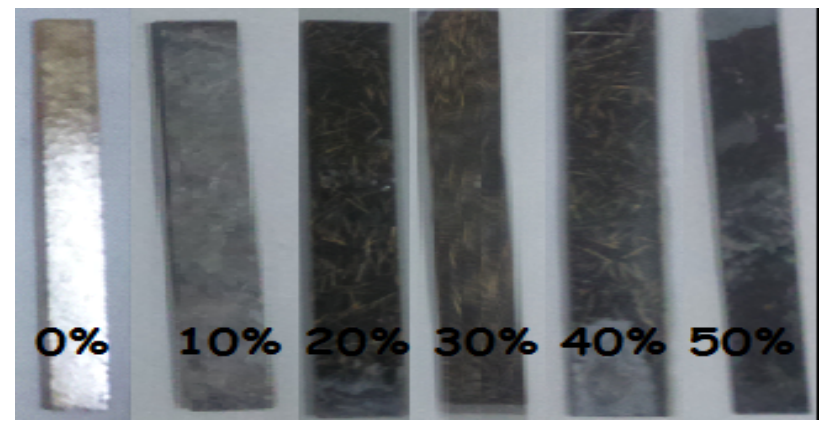

Primeiro foi feita a pesagem dos componentes da mistura e da fibra de coco. Em seguida passasse ao processo de mistura propriamente dita, em um béquer contendo a resina é adicionado o inciador, MET ( retarda o processo de endurecimento da resina), após adicionase o resíduo à mistura, em seguida adiciona-se o acelerador, MEK-P. 
Terminada a preparação da mistura, a mesma é distribuída no molde em cima das fibras já dispostas de forma randômica. Ao atingir o ponto de gel, a mistura é derramada sobre a forma e espera-se até 15 minutos até o ponto de cura do material. Depois dos 15 minutos, o molde é fechado levada à pressão de $5 \mathrm{KN}$ por um período pré-determinado de 20 minutos. A placa é então desenformada e segue para o processo de corte. Na Figura 5 podemos ver o molde utilizado para a conformação das placas.

Figura 5 - Molde metálico com sistema de parafusos Allen para produção das placas de compósitos.

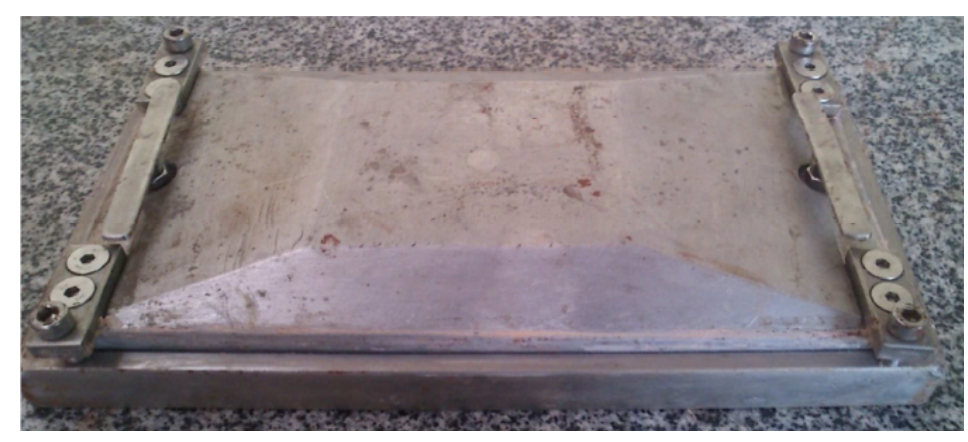

As placas contendo 0\% de RMG foram adotadas como padrão de comparação para as placas contendo o rejeito, sendo assim, foram confeccionados compósitos com 10, 20, 30, 40, $50 \%$ de carga. Aderiu-se, para bases de cálculo, $10 \%$ de erro para os valores dos materiais, levando-se em conta o material perdido em todo o processo de confecção.

Para realização dos testes de MEA, PA e AA, foram calculados primeiramente os valores de massa seca, massa úmida e massa imersa de cada um dos corpos retangulares confeccionados para cada mistura. Os compósitos ficaram imersos em água por um período de 24 horas para obtenção dos valores de massa imersa e massa úmida. De posse dos valores mássicos, as Equações (1), (2) e (3) foram utilizadas para a obtenção dos valores das propriedades dos materiais obtidos:

$$
\begin{aligned}
& M E A=M S\left(\mathrm{~g} / \mathrm{cm}^{3}\right) \\
& P A=\frac{M U-M S}{M U-M I} \times 100 \\
& A A=\frac{M U-M S}{M S} X 100
\end{aligned}
$$

MS: Massa seca; MU: Massa úmida; MI: Massa Imersa.

\section{RESULTADOS E DISCUSSÕES}

Umidade: A umidade encontrada para o material do material coletado foi de $32,3 \%$.

Massa Específica Aparente (MEA): Através da Equação (1), vista acima, calculou-se o valor de MEA de cada corpo de prova, em seguida encontrou-se o valor médio para cada 
mistura. A Figura 6 apresenta os valores obtidos a partir da comparação dos valores médios de cada.

Figura 6 - Variação da MEA em função do teor de resíduo no compósito

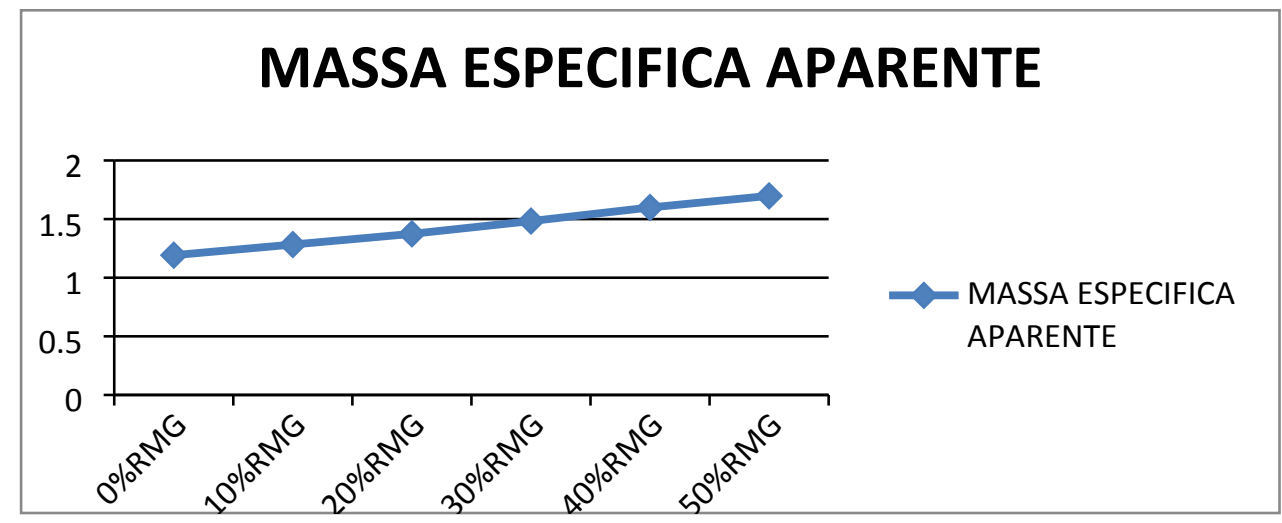

De acordo com o gráfico o aumento do teor de RMG na mistura ocasiona o aumento da MEA, devido ao valor da densidade do resíduo ser superior ao valor da densidade da resina.

Porosidade Aparente (PA) e Absorção de Água(AA): Através da Equação (2) e da Equação (3), foram obtidos os valores da PA e AA média para cada corpo de prova. As Figuras 7 e 8 mostram os valores obtidos a partir da comparação dos valores dessas duas propriedades em função do teor de RMG no compósito.

Figura 7 - Gráfico da variação da PA em função do teor de resíduo no compósito

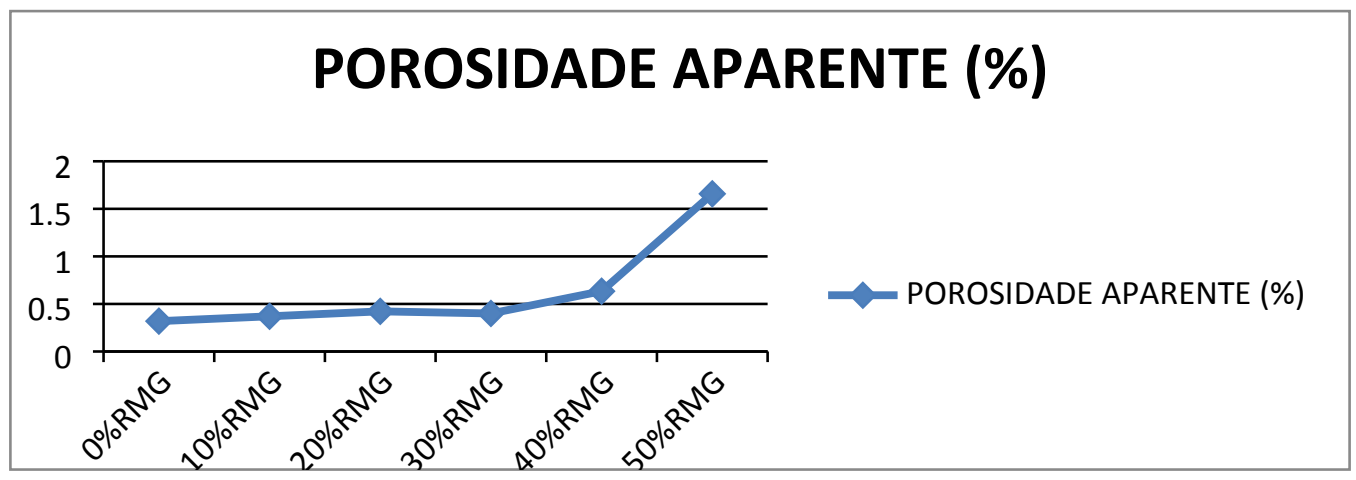

Fig. 8: Gráfico da variação da MEA em função do teor de resíduo no compósito. 

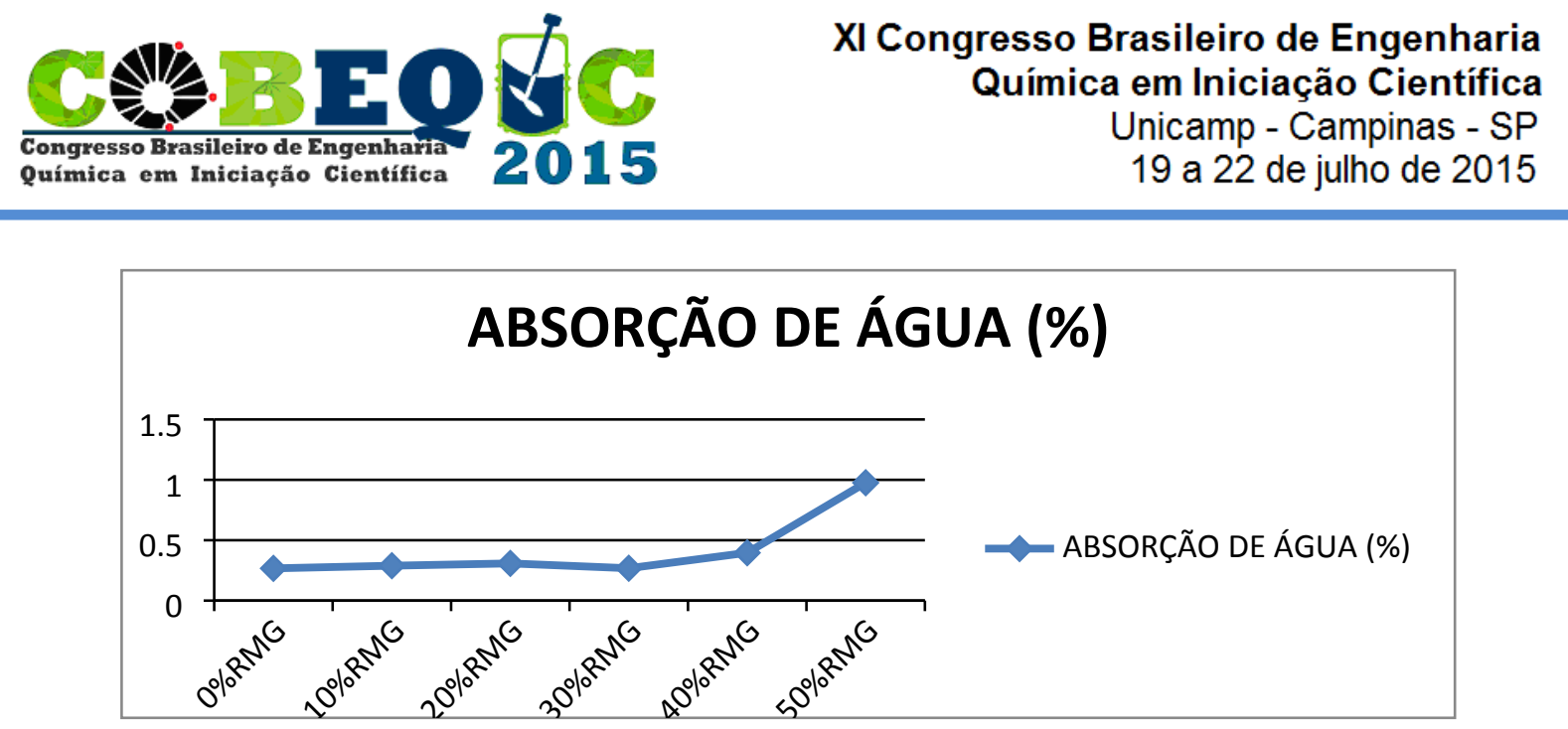

Como podemos observar essas duas propriedades estão diretamente ligadas, quanto maior a porosidade aparente maior absorção de água. No entanto, é notável que a mistura de 50 $\%$ de RMG obteve valores acentuados dessas propriedades. Portanto, analisando-se as Figuras 2 e 3 podemos verificar que essas propriedades são consideravelmente sensíveis à variação do teor de carga na mistura. Em decorrência dos valores variáveis de PA e AA, é indispensável um estudo mais detalhado quanto à suscetibilidade dessas propriedades ao teor de carga presente no compósito.

\section{CONCLUSÃO}

Diante dos níveis de poluição e do crescente mercado comercial, espera-se que o desenvolvimento de novos materiais e processos esteja não somente ligados aos aspectos econômicos, mas também aos aspectos ambientais e sociais. Neste contexto, o presente trabalho mostrou ser possível a incorporação do RMG para confecção de compósitos ecológicos para possíveis aplicações em áreas como a construção civil, no entanto há a necessidade de estudos mais detalhados e dependendo da finalidade um maior cuidado com o acabamento do produto.

\section{NOMENCLATURA}

RMG - Resíduo de mármore e granito

AA - Absorção de água

PA - Porosidade aparente

MEA - Massa específica aparente

\section{REFERÊNCIAS}

FERREIRA, A. C. B.; NUNES, E. C. D. Reaproveitamento e incorporação de resíduo de mármore em poliamida 66. 2007.

FERRAZ, Joana Mendes. Produção e propriedades de painéis de fibra de coco (Cocos Nucifera L.) em mistura com cimento Portland. 2011. 98 f. Dissertação (Mestrado) Faculdade de Tecnologia, Departamento de Engenharia Florestal, Universidade de Brasília, Distrito Federal, 2011.

MOREIRA, J. M. S.; FREIRE, M. N.; HOLANDA, N. F. Utilização de resíduo de serragem de granito proveniente do estado do Espírito Santo em cerâmica vermelha. Cerâmica, v. 49, p. 262-267, 2003. 
XI Congresso Brasileiro de Engenharia Química em Iniciação Científica 